the use of genetically engineered mice to provide validated models for drug discovery efforts precarious ${ }^{6}$.

\title{
Magic shotguns versus magic bullets: selectively non-selective drugs for mood disorders and schizophrenia
}

\author{
Bryan L. Roth, Douglas J. Sheffler and Wesley K. Kroeze
}

\begin{abstract}
Most common central nervous system disorders - such as depression, bipolar disorder and schizophrenia - seem to be polygenic in origin, and the most effective medications have exceedingly complex pharmacologies. Attempts to develop more effective treatments for diseases such as schizophrenia and depression by discovering drugs selective for single molecular targets (that is, 'magic bullets') have, not surprisingly, been largely unsuccessful. Here we propose that designing selectively non-selective drugs (that is, 'magic shotguns') that interact with several molecular targets will lead to new and more effective medications for a variety of central nervous system disorders.
\end{abstract}

Despite their enormous potential to alleviate human suffering, before the introduction of fluoxetine (Prozac; Eli Lilly) in the late 1980s central nervous system (CNS) therapeutics were not widely embraced as either highly reliable or profitable. This is despite the fact that from the 1960s to the 1970s selected areas of CNS drug discovery yielded profitable drugs (for example, Valium, Milltown and Haldol). This was due, in part, to the lack of suitable animal models, disagreements regarding the biological basis of many disorders, uncertainty regarding the ultimate mechanism(s) of action and the clinical ineffectiveness of many CNS medications ${ }^{1}$. During the past two decades, CNS drug discovery - particularly in the areas of mood disorders and schizophrenia - has become one of the most profitable sectors of the pharmaceutical market. CNS drugs account for 11 of the top 25 drugs on the US market, with annual US sales in excess of US \$17 billion (2002 sales figures). Additionally, it is now widely accepted that moderately effective treatments exist for most of the common CNS diseases, including schizophrenia, depression, anxiety disorders, insomnia, migraine headaches, chronic pain and seizure disorders. This article will focus on the two largest sectors of the CNS drug market: atypical antipsychotic drugs for schizophrenia and related disorders, and antidepressants for depression and anxiety disorders.

Despite the acknowledged potential of CNS therapeutic agents, few drugs with truly novel mechanisms of action have been introduced in the past several decades. Indeed, the most widely prescribed drugs - the serotoninselective reuptake inhibitors (SSRIs) and atypical antipsychotic drugs - represent only marginal advances over the prototypes zimelidine (discovered in 1971 (REF. 2)) and clozapine (discovered in 1958 (REF.3)).

Because the aetiology of depression and schizophrenia is unknown, choosing the appropriate molecular target for drug discovery is especially risky. In terms of aetiology, it is now widely accepted that the major mental illnesses are polygenic ${ }^{4,5}$, with substantial environmental and, perhaps, epigenetic components. The polygenic and non-genetic components of major CNS diseases makes
Another fundamental difficulty with developing novel CNS therapeutics is the appreciation that the most widely prescribed CNS medications, especially those for mood disorders (for example, lithium, anticonvulsants and antidepressants ${ }^{7}$ ) and schizophrenia ${ }^{8}$ have complex and ill-defined mechanisms of action. As will be summarized below, the discovery that the most clinically effective CNS drugs are pharmacologically complex, with pleiotypic actions (that is, they act as 'magic shotguns'), has made the development of 'magic bullets' (that is, drugs selective for a single molecular target) less likely.

\section{Why 'dirty' drugs might be better}

Even though clozapine was discovered nearly 50 years ago ${ }^{3}$, it remains the 'gold standard' atypical antipsychotic drug because of the absence of debilitating extra-pyramidal sideeffects and demonstrated clinical superiority in treating schizophrenia ${ }^{9}$ and in reducing suicidality ${ }^{10}$. However, clozapine is also associated with severe and potentially lifethreatening side effects, including an increased risk of agranulocytosis, seizures, weight gain and diabetes, and is therefore typically prescribed only for individuals with 'treatmentresistant' schizophrenia. Clozapine has a highly complex pharmacological profile, with high affinity for a number of serotonin $\left(5-\mathrm{HT}_{2 \mathrm{~A}}\right.$, $\left.5-\mathrm{HT}_{2 \mathrm{C}}, 5-\mathrm{HT}_{6}, 5-\mathrm{HT}_{7}\right)$, dopamine $\left(\mathrm{D}_{4}\right)$, muscarinic $\left(M_{1}, M_{2}, M_{3}, M_{4}, M_{5}\right)$, adrenergic $\left(\alpha_{1}-\right.$ and $\alpha_{2}$-subtypes) and other biogenic amine receptors (REF. 8 and references cited therein).

FIGURE 1 shows the distribution of some of the receptors targeted by clozapine in relation to various molecular targets implicated by genetic studies of schizophrenia (see REFS 4,5 for details). As can be seen in FIG. 1, many of the genes implicated in the aetiology of schizophrenia are found in anatomical loci where they could, directly or indirectly, modulate glutamatergic and dopaminergic neurotransmission in the frontal cortex. Clozapine is 
thought to normalize glutamatergic and dopaminergic neurotransmission in schizophrenia, thereby ameliorating symptoms, via complex interactions with a large number of molecular targets (FIGS 1,2). These pleiotypic actions of clozapine are probably responsible for its exceptionally beneficial actions in schizophrenia and related disorders ${ }^{9,10}$.

A graphical representation of the relative affinity values of clozapine and a number of other atypical antipsychotic drugs (aripiprazole, ziprasidone, zotepine, quetiapine, olanzapine, risperidone) and typical antipsychotic drugs (haloperidol, chlorpromazine) at a portion of the receptorome (that is, that portion of the proteome comprising receptors) is shown in FIG. 2. As can be seen, most of the presently approved atypical antipsychotic drugs have a complex pharmacology, with appreciable affinities for a variety of biogenic amine receptors. Given the huge potential market for atypical antipsychotic drugs ( $\sim$ US $\$ 10$ billion annually), great effort has been devoted to uncovering the receptors responsible for effectiveness, for atypicality and for side effects. The idea has been that if one could design drugs that targeted the appropriate receptors, one could develop atypical antipsychotic drugs that are more effective than clozapine and have fewer side effects. These efforts will be furthered in the future by the precise delineation of the areas of the brain in which the drug exerts its beneficial effects, as well as characterization of the intracellular biochemical pathways contributing to both effectiveness and the development of side effects.

\section{' $S_{2} / D_{2}$ ' drugs: not quite clozapine}

The first 'non-clozapine' atypical to be marketed was risperidone, which potently blocks the effects of lysergic acid diethylamide (LSD) in laboratory animals by virtue of its high affinity for $5-\mathrm{HT}_{2 \mathrm{~A}}$ receptors ${ }^{11}$. A systematic analysis of receptor pharmacology of a number of typical and atypical antipsychotic drugs led Meltzer ${ }^{12}$ and others ${ }^{13}$ to propose that the single distinguishing feature of an atypical antipsychotic drug was a relatively high affinity for $5-\mathrm{HT}_{2 \mathrm{~A}}$ relative to $\mathrm{D}_{2}$ receptors (the ' $\mathrm{S}_{2} / \mathrm{D}_{2}$ hypothesis of atypicality'). Subsequently, several atypical antipsychotic drugs were introduced that fulfilled the ' $\mathrm{S}_{2} / \mathrm{D}_{2}$ ' criterion, including olanzapine, ziprasidone, zotepine and quetiapine. Although these drugs represent an advance in the treatment of schizophrenia, none of the presently approved atypical antipsychotic drugs is better than clozapine for schizophrenia ${ }^{14,15}$. As a class, the ' $\mathrm{S}_{2} / \mathrm{D}_{2}$ atypicals' are not without serious side effects, including weight gain and the associated metabolic sequelae of diabetes and

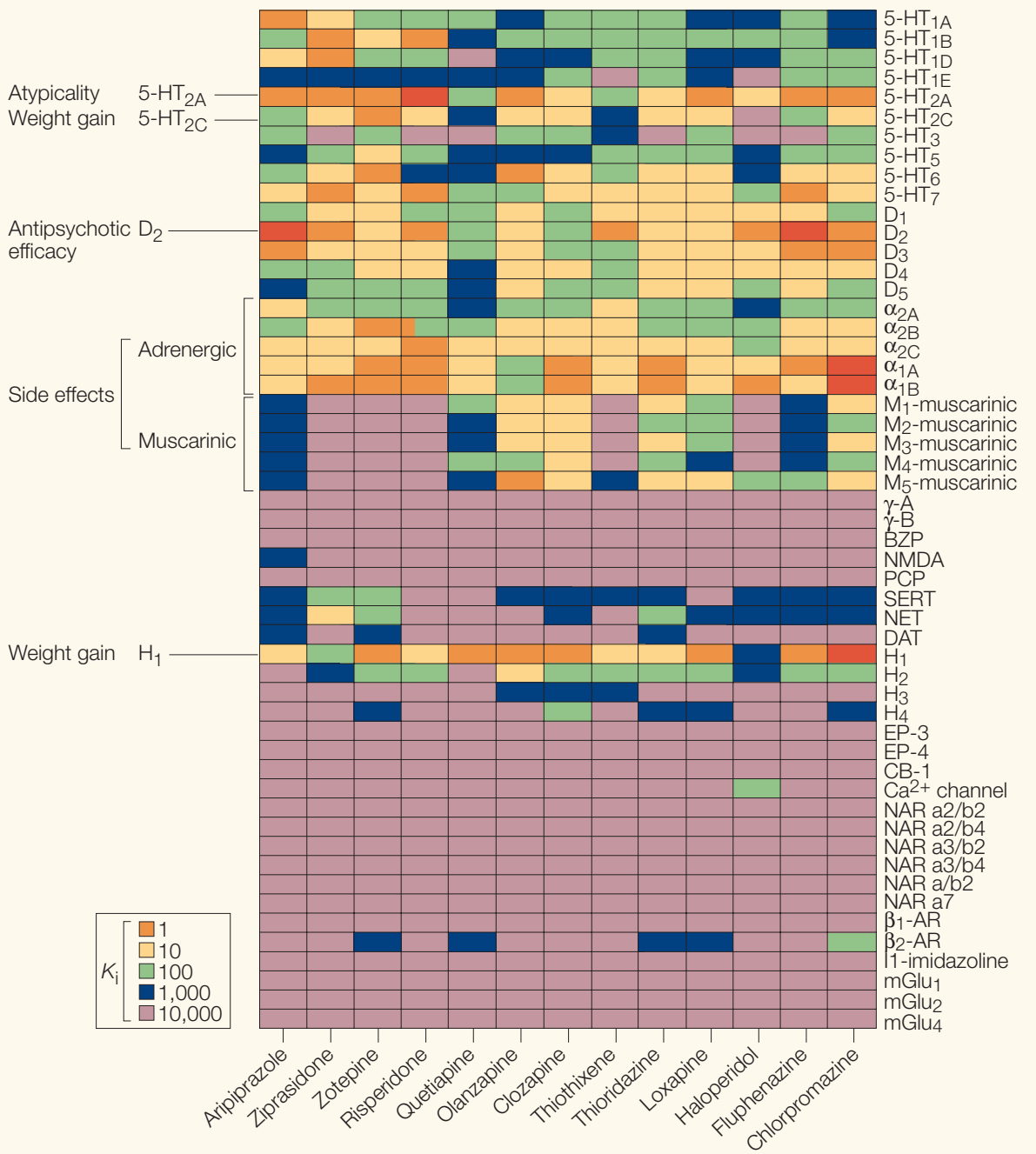

Figure 2 | Screening the receptorome reveals multiple molecular targets implicated in

antipsychotic drug actions. The affinity $\left(K_{j}\right)$ values for clozapine and a large number of other biologically active compounds at various receptors can be found at the PDSP $K_{\mathrm{i}}$ Database (see Further Information); the database is part of the National Institute of Mental Health Psychoactive Drug Screening Program (see Further Information) and represents the largest database of its kind in the public domain. At present, the PDSP $K_{i}$ database has $>26,000 K_{i}$ values for more than 300 receptors.

hypercholesterolaemia ${ }^{16}$. In this regard, recent studies have implicated the histamine receptor $\mathrm{H}_{1}$, the 5- $\mathrm{HT}_{2 \mathrm{C}}$ receptor and $\alpha_{1}$-adrenoceptors — sites for which many atypical antipsychotic drugs have high affinity — for causing weight gain and associated metabolic side effects ${ }^{17}$. $\mathrm{S}_{2} / \mathrm{D}_{2}$ atypicals that have relatively low affinity for $H_{1}$ receptor and $\alpha_{1}$-adrenoceptors (for example, ziprasidone) are less likely to induce weight gain. Because other CNS medications that induce weight gain, such as amitryptiline, mirtazepine and imipramine (see PDSP $K_{i}$ Database, Further Information), also have high $\mathrm{H}_{1}, 5-\mathrm{HT}_{2 \mathrm{C}^{-}}$and $\alpha_{1}$-adrenoceptor affinities, these data strongly imply that antipsychotic drugs that lack affinities at $\mathrm{H}_{1}$, $5-\mathrm{HT}_{2 \mathrm{C}}$ and $\alpha_{1}$ receptors will be less likely to induce the metabolic side effects of many of the presently marketed drugs.
In addition to improving the core symptoms of schizophrenia, such as hallucinations and delusions, atypical antipsychotic drugs as a class modestly improve cognition ${ }^{18}$, though it is unknown how these cognition-enhancing actions are mediated. Current hypotheses suggest that the cognition-enhancing actions of atypicals may be due to interactions with $5-\mathrm{HT}_{2 \mathrm{~A}}{ }^{19}$ and $5-\mathrm{HT}_{6}{ }^{20}$ receptors, and to their abilities to enhance prefrontal cortical dopamine release ${ }^{21}$ (FIG. 1).

Many attempts, largely unsuccessful, have been made to develop drugs that target the 'magic receptor' responsible for clozapine's salutary effects in schizophrenia and related disorders and, thereby, yield novel atypical antipsychotic drugs. For instance, $\mathrm{D}_{4}$-selective compounds ${ }^{22}$, as well as compounds with $5-\mathrm{HT}_{2 \mathrm{~A}} / \mathrm{D}_{4}$ antagonism ${ }^{23}$, are ineffective in 


\begin{tabular}{|c|c|c|c|c|}
\hline Receptor & $\begin{array}{l}\text { Representative } \\
\text { compound }\end{array}$ & $\begin{array}{l}\text { Results versus } \\
\text { placebo }\end{array}$ & $\begin{array}{l}\text { Results versus } \\
\text { comparator }\end{array}$ & References \\
\hline $5-\mathrm{HT}_{2 \mathrm{~A}}$ & M100907 & Better & Worse & \\
\hline $5-\mathrm{HT}_{2 \mathrm{~A} / 2 \mathrm{C}}$ & SR46349B & Better & Similar & 25 \\
\hline $5-\mathrm{HT}_{6}$ & SB271046 & In Phase I & NA & ${ }^{*}$ see footnote \\
\hline $5-\mathrm{HT}_{2 \mathrm{~A}} / \mathrm{D}_{4}$ & Fananserin & $\begin{array}{l}\text { Potentially worse or } \\
\text { similar to placebo }\end{array}$ & NA & 23 \\
\hline $\begin{array}{l}\mathrm{D}_{2} \text {-dopamine } \\
\text { partial agonist }\end{array}$ & (-)PPP & $\begin{array}{l}\text { Worse with } \\
\text { moderate efficacy }\end{array}$ & NA & 28 \\
\hline $\begin{array}{l}\mathrm{D}_{3} \text {-dopamine } \\
\text { partial agonist }\end{array}$ & (+)-UH232 & Worse & NA & 29 \\
\hline$D_{3}$-dopamine & SB-277011 & In trials & NA & 52 \\
\hline $\mathrm{D}_{4}$-dopamine & L-745,870 & $\begin{array}{l}\text { Potentially worse or } \\
\text { similar to placebo }\end{array}$ & NA & 53 \\
\hline $\begin{array}{l}\mathrm{CB}_{1} \\
\text { cannabinoid }\end{array}$ & SR-141716 & Worse & Worse & 25 \\
\hline Sigma & BMY-14802 & Similar to placebo & NA & 54 \\
\hline Sigma & Panamesine & Better (small trial) & NA & 55 \\
\hline $\mathrm{NK}_{3}$ & SR142801 & Better & Same & 25 \\
\hline $\mathrm{NT}_{1}$ & SR48692 & Worse & Worse & 25 \\
\hline Glutamate & D-cycloserine & $\begin{array}{l}\text { Similar to placebo with } \\
\text { marginal effect on negative } \\
\text { symptoms; may augment } \\
\text { actions of atypical } \\
\text { antipsychotic drugs }\end{array}$ & NA & 56,57 \\
\hline
\end{tabular}

* See http://science.gsk.com/pipeline/pipeline2002oct.pdf for details. 5-HT, serotonin; NK, neurokinin; NT, neurotensin.

treating schizophrenia. Likewise, the $5-\mathrm{HT}_{2 \mathrm{~A}}$ selective compound M100907 (REF. 24) failed to reduce symptoms to the same extent as haloperidol (a typical antipsychotic drug comparator) in a multi-centre clinical trial, whereas the 5- $\mathrm{HT}_{2 \mathrm{~A} / 2 \mathrm{C}}$ antagonist SR46349B fared better in comparison with haloperidol ${ }^{25}$ (TABLE 1). There have also been suggestions that compounds with muscarinic ${ }^{26}$ or adrenoceptors (both $\alpha_{2}$ - and $\alpha_{1}$-adrenoceptors) actions might be effective antipsychotic drugs but, so far, none have shown efficacy in clinical trials (see REF. 8 and references cited therein). TABLE 1 lists a number of other 'magic bullets' which, with few exceptions, were shown to lack efficacy in schizophrenia.

\section{Partial agonists for schizophrenia}

Some years ago, Carlsson proposed that (-)3-(3-hydroxyphenyl)- $N$-n-propylpiperidine ((-)PPP), by virtue of its autoreceptor agonist properties, might represent a prototype for a new family of atypical antipsychotic drugs ${ }^{27}$. Carlsson's notion was that a partial agonist would normalize or 'stabilize' dopaminergic neurotransmission in a way that would be salutary for both the positive and negative symptoms of schizophrenia. Two potential compounds were subsequently tested: (-)PPP and (+)-UH232 ( a D $_{3}$-preferring agonist with $5-\mathrm{HT}_{2 \mathrm{~A}}$ agonism). When (-)PPP was tested in schizophrenia, it was found to be effective for a short period ( $\sim$ one week), after which clinical efficacy was lost - presumably due to receptor desensitization ${ }^{28}$. Because (-)PPP has substantial affinities for non- $\mathrm{D}_{2}$ receptors (for example, $\sigma_{-}, \alpha_{2 B}-$ or $\alpha_{2 C}$-adrenoceptors; see PDSP Database, Further Information), it is conceivable that the ineffectiveness of (-) PPP was due to unforeseen interaction with non- $\mathrm{D}_{2}$ receptors. Intriguingly, (+)-UH232 actually worsened psychotic symptoms, perhaps via a combination of $\mathrm{D}_{3}$ and $5-\mathrm{HT}_{2 \mathrm{~A}}$ agonism $^{29}$, because $5-\mathrm{HT}_{2 \mathrm{~A}}$ agonism is known to exacerbate psychosis ${ }^{62}$.

On the basis of these early trials, it was unclear whether (-)PPP's lack of efficacy beyond one week was due to either inadvertent interaction with psychotomimetic receptors (for example, $\sigma_{1}$-adrenoceptor) or the relatively high intrinsic activity of (-)PPP leading to desensitization. Several other $\mathrm{D}_{2}$ partial agonists, including terguride, OPC-4392, pramipexole and SDZ HDC 912, have now been tested in schizophrenia, mainly unsuccessfully $^{30}$. To date, only aripiprazole (OPC 14597), a weak $D_{2}$ partial agonist ${ }^{31}$, has shown efficacy for schizophrenia ${ }^{32}$, although considerable controversy exists regarding its mechanism of action (BOX 1).

Kikuchi et al. ${ }^{31}$ originally proposed that aripiprazole was a presynaptic agonist and a postsynaptic antagonist and would therefore 'stabilize' dopaminergic neurotransmission. This notion of 'anatomical selectivity' is difficult to reconcile with later findings that aripiprazole is a $\mathrm{D}_{2}$ partial agonist at postsynaptic pituitary $\mathrm{D}_{2}$ receptors in vitro and in vivo ${ }^{33}$. Likewise, the $\mathrm{D}_{2}$ partial agonism has been inconsistently replicated, with some groups reporting that aripiprazole is a highaffinity partial agonist in vitro ${ }^{34}$, and others reporting that aripiprazole is $\mathrm{D}_{2}$ antagonist in vivo and in vitro ${ }^{35}$. By contrast, Lawler et al. ${ }^{36}$ proposed that aripiprazole was 'functionally selective' and that the agonist properties of aripiprazole were entirely dependent on the cellular milieu in which it was studied. As a result, it was proposed ${ }^{36}$ that aripiprazole might function as a $\mathrm{D}_{2}$ antagonist, agonist or partial agonist depending on the precise complement of $\mathrm{D}_{2}$ receptors and $\mathrm{G}$-proteins in a particular cell. This notion is similar to the idea of agonist-directed trafficking of receptors (see REF. 37 for a recent review), an idea originally proposed many years ago ${ }^{38}$. This idea proposes that receptors can couple to several signal transducing molecules and suggests that "selective agonists and antagonists might be developed which have specific effects on a particular receptor-linked effector system." 38

When the various competing hypotheses of aripiprazole's actions were tested, we found ${ }^{39}$, in support of the hypothesis of Lawler et al. ${ }^{36}$, that the actions of aripiprazole were entirely dependent on the cellular milieu. Interestingly, we also discovered ${ }^{39}$ that aripiprazole had a robust pharmacological profile with partial agonism at several 5-HT $\left(5-\mathrm{HT}_{1 \mathrm{~A}}, 5-\mathrm{HT}_{2 \mathrm{~A}}, 5-\mathrm{HT}_{2 \mathrm{C}}, 5-\mathrm{HT}_{7}\right)$ and dopamine $\left(\mathrm{D}_{2}, \mathrm{D}_{3}, \mathrm{D}_{4}\right)$ receptors. So although aripiprazole is clearly a functionally selective partial agonist, its complex pharmacology precludes us from concluding that its beneficial actions in schizophrenia are due solely to partial agonism of $\mathrm{D}_{2}$ receptors. It is more likely that the balance of partial agonism and antagonism at a multiplicity of receptors is responsible for its efficacy in schizophrenia and related disorders. Taken together, these findings have profound implications for CNS drug discovery, because they imply that simply developing selective low-efficacy $\mathrm{D}_{2}$ partial agonists will not yield effective antipsychotic drugs, but that $\mathrm{D}_{2}$ partial agonists that functionally interact with various 5-HT and dopamine receptors might be effective. Therefore functionally non-selective dopamine agonists might represent a new generation of atypical antipsychotic drugs, with aripiprazole being the first member of this class. 


\section{Non-selective antidepressants?}

If 'dirty' drugs are better for treating schizophrenia than selective ('clean') ones, what about other CNS disorders? TABLE 2 lists the current classes of antidepressants, ranking them by their relative effectiveness in treating depression. The most effective treatment for depression - electroconvulsive therapy (ECT) - alters the dynamics of a vast number of neurotransmitters and neuromodulators, and has profound effects on intracellular signalling pathways related to signal transduction and mitogenesis ${ }^{7}$. Indeed, very recent studies imply that the pleiotypic actions of antidepressants on signal transduction and neuronal mitogenesis are required for the beneficial actions of antidepressants on $\operatorname{mood}^{40}$. Likewise, so-called 'dual-action' antidepressants, which inhibit the reuptake of both 5-HT and other biogenic amines (for example, dopamine and noradrenaline), have been shown to be more effective than 'single-action' antidepressants such as the SSRIs ${ }^{41,42}$. As an added benefit, the 'dualaction' antidepressants also seem to effectively treat chronic pain ${ }^{43}$. Finally, recent genetic studies have implied that depression, like schizophrenia, is a complex disorder with linkage to several genes ${ }^{44}$, including many that converge on the transcription factor cAMP-responsive element binding protein-1 (CREB1). These results imply that improved treatments for mood disorders are likely to arise from drugs with several mechanisms of action, and that studies that connect new knowledge of genetic linkage of these diseases in humans with those of changes in gene regulation in disease, as well as after treatment, are likely to be helpful in the development of new therapies.

\section{Implications for CNS drug discovery}

Given that selectively non-selective drugs are likely to be more beneficial than singleaction agents in many CNS disorders, how best to develop them? Clearly, conventional approaches relying on high-throughput screening (HTS) of cloned human molecular targets and the subsequent optimization of these 'single-target agents' is not likely to yield selectively non-selective agents, except, perhaps, by chance. Structure-based drug design approaches in which ligands are designed to interact with the correct subset of molecular targets are also not likely to be successful. This is because many of the molecular targets selected have a high degree of structural similarity and designing drugs to target a subset of them is not likely to be successful (see REF. 63 for discussion).

The implication of these findings is that the screening of small molecules by nonconventional approaches should be considered.
Conceptually, at least two non-conventional approaches for discovering 'magic shotguns' can be envisioned: behaviour-based screening and genomic approaches. The first, which has been dubbed 'HTS'-based behavioural screening ${ }^{35,46}$, relies on the semi-automated screening of candidate drugs in broad-based behavioural assays. At least two novel antidepressants - YKP10A and INN 00835 were discovered using this approach. Neither drug seems to have appreciable affinity for any known antidepressant drug target, including various biogenic amine receptors and transporters $^{47}$, and both have demonstrated effectiveness in early-phase trials ${ }^{48,47}$. It is probable that the large-scale, automated and random screening of libraries of compounds enriched for activity at CNS targets, using mainly behavioural assays, will yield compounds with novel and, possibly improved, efficacies for a variety of CNS diseases. These approaches carry with them the advantage of examining responses to drugs at the level of entire organisms, and therefore in the context of their biological functioning, rather than in overly simplified experimental systems, for example, as in isolated in vitro binding studies.

Another approach is a genomic one in which compounds are screened solely on the basis of their abilities to modify the

\section{Box 1 | Partial functionally selective agonists for schizophrenia?}

The figure shows three different proposed models of aripiprazole action. In these various models, receptors coloured green are activated by aripiprazole and those coloured red are antagonized; receptors colourd yellow can be partially activated by aripiprazole, depending on the assay conditions. In panel a, the anatomical specificity model is highlighted. This model originally proposed that partial agonists which are effective in treating schizophrenia have differential actions at pre- and postsynaptic $\mathrm{D}_{2}$ dopamine receptors ${ }^{31}$. This model proposed that aripiprazole, for instance, is a presynaptic agonist and a postsynaptic antagonist; these dual actions thereby 'normalize' dopaminergic signalling. In panel $b$, the density-dependent partial agonist model $^{34}$ is shown schematically. This model, which relies on classical receptor theory, proposes that aripiprazole is a partial agonist whose actions depend solely on the relative density of $\mathrm{D}_{2}$-dopamine receptors. As such, in brain regions in which relatively high concentrations of $\mathrm{D}_{2}$-dopamine receptors exist, drugs like aripiprazole would be partial agonists, whereas in brain regions with relatively low concentrations of $\mathrm{D}_{2}$ receptors exist aripiprazole would function as an antagonist. In panel c, we show our conceptualization of the functional selectivity model. This model proposes that aripiprazole's partial agonist actions at a variety of G-protein-coupled receptors (GPCRs) are dependent on the precise cellular complement of receptors and G-proteins ${ }^{36}$ and relies on our current understanding of GPCR actions. This model predicts that partial agonists, such as aripiprazole, will have a multiplicity of actions, functioning as agonists, partial agonists or antagonists. Indeed, recent studies indicate that the functional selectivity model best explains aripiprazole's actions ${ }^{39}$.

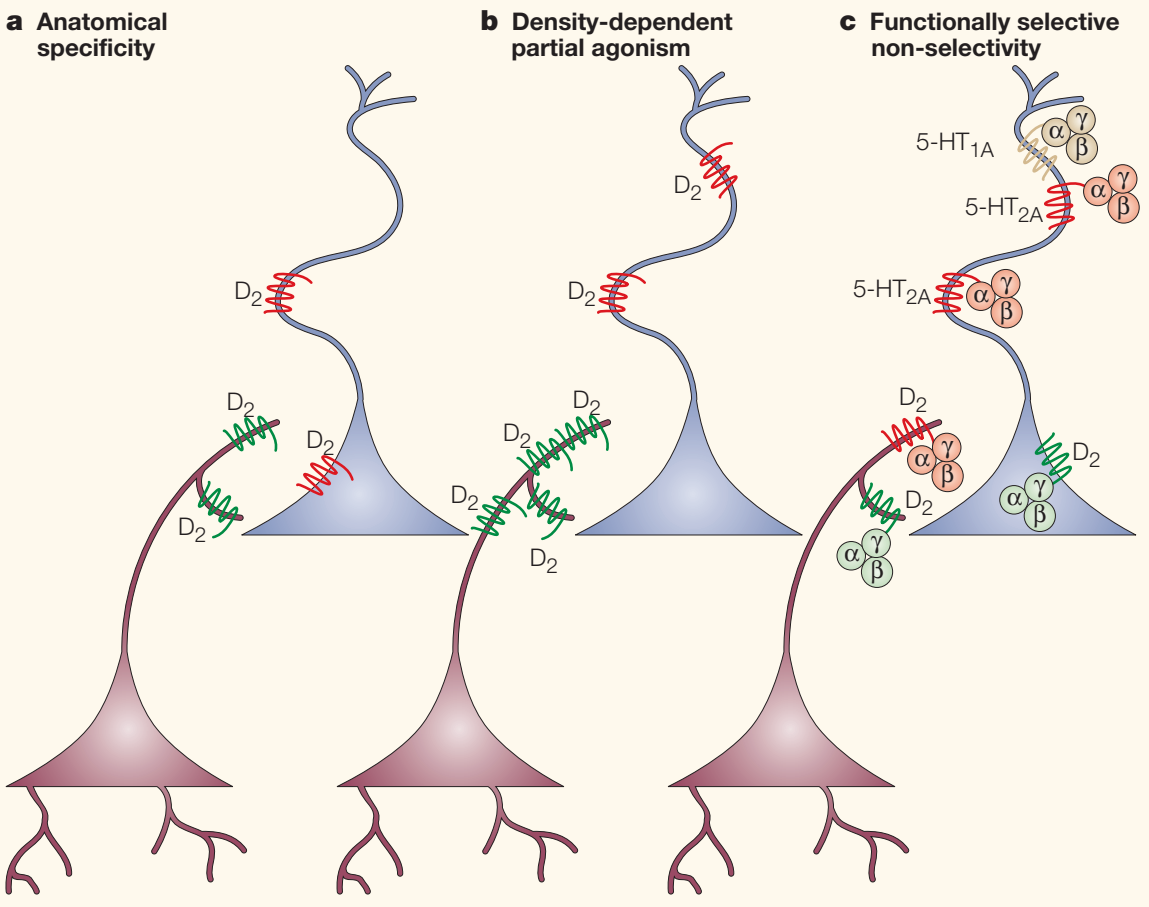


coordinated expression of gene families. In this approach, compounds with known beneficial actions and pleiotypic actions (for example, lithium, clozapine) are screened in vivo and in vitro for their effects on coordinated gene expression. Once gene 'signatures' are discovered, compound libraries are subsequently screened to discover small molecules which, when administered in vitro and in vivo, yield similar signatures; such an approach is now being undertaken by Psychiatric Genomics, Inc. ${ }^{49}$. Lead compounds can then be optimized to eliminate interactions with potentially toxic molecular targets (for example, $\mathrm{H}_{1}$ receptor for weight gain ${ }^{17}$, human ether-a-go-go-related gene $\mathrm{K}^{+}$channel for arrhythmias ${ }^{50}$ and the $5-\mathrm{HT}_{2 \mathrm{~B}}$ receptor for fenfluramine-like valvular heart disease $\left.{ }^{51}\right)$. In addition, it might prove possible to use combinations of compounds to 'fine-tune' these gene regulatory signatures.

\section{The end of serendipity?}

Historically, serendipity has been the driving force in the discovery of novel and highly effective drugs for CNS disorders. Not surprisingly, the most clinically effective treatments for depression and schizophrenia, and perhaps other disorders, continue to be the ones with the most nonspecific actions. It is likely that selectively non-selective drugs - 'magic shotguns' — could be discovered by combining behavioural and genomics-based screening. Once leads are discovered, potential toxicities could be relatively easily 'designed out' by counter-screening approaches combined with straight-forward medicinal chemistry approaches. Such magic shotguns, or selectively non-selective drugs, are likely to represent highly effective and novel treatments for major CNS disorders. The rational discovery, optimization and eventual marketing of selectively non-selective drugs will end our reliance on serendipity as the driving force for effective drug discovery for CNS disorders. On the other hand, in a

\section{Table 2 | Antidepressants with complex modes of action are superior to single-action antidepressants

\begin{tabular}{|c|c|c|c|c|c|c|}
\hline $\begin{array}{l}\text { Prototypical } \\
\text { drug }\end{array}$ & Class & Mode* & $\begin{array}{l}\text { Molecular } \\
\text { target(s) }\end{array}$ & Phase of testing & Efficacy vs SSRI & Company \\
\hline $\begin{array}{l}\text { Electro- } \\
\text { convulsive }\end{array}$ & Somatic therapy & $\mathrm{C}$ & Undefined & In use for decades & Greater efficacy ${ }^{58}$ & None \\
\hline
\end{tabular}

therapy

$\begin{array}{llll}\text { Imipramine } & \begin{array}{l}\text { Tricyclic } \\ \text { antidepressant }\end{array} & \mathrm{C} & \mathrm{NET}, \mathrm{SERT}, \\ & & 5-\mathrm{HT}_{2 \mathrm{~A}}, 5-\mathrm{HT}_{2 \mathrm{C}}, \\ & & 5-\mathrm{HT}_{6}, \alpha_{1} \text {-adren- } \\ & & \text { ergic, muscarinic } \\ & & \text { SERT }\end{array}$

$\begin{array}{ll}\text { Venlafaxine } & \begin{array}{l}\text { Dual serotonin/ } \\ \text { norepinephrine } \\ \text { reuptake inhibitor }\end{array}\end{array}$

Pindolol

$5-\mathrm{HT}_{1 \mathrm{~A}}$ partial
agonist/SSRI

NET; SERT In

In use for $>10$ years N/A Eli Lilly

use 10 years

Slight advantage ${ }^{41,42,59} \quad$ Wyeth

Several double-blind, placebo controlled clinical trials completed; both drugs approved for use

\begin{tabular}{|c|c|}
\hline Duloxetine & $\begin{array}{l}\text { Dual serotonin/ } \\
\text { norepinephrine } \\
\text { reuptake inhibitor }\end{array}$ \\
\hline Gepirone & $\begin{array}{l}5-\mathrm{HT}_{1 \mathrm{~A}} \text { partial } \\
\text { agonist }\end{array}$ \\
\hline
\end{tabular}

\section{C} NET; SERT

S $\quad 5-\mathrm{HT}_{1 \mathrm{~A}}$

$5-\mathrm{HT}_{1 \mathrm{~A}}$

A

NDA submitted; several 5- $\mathrm{HT}_{1 \mathrm{~A}}$ partial agonists have been previously tested as single agent treatments for depression with modest success

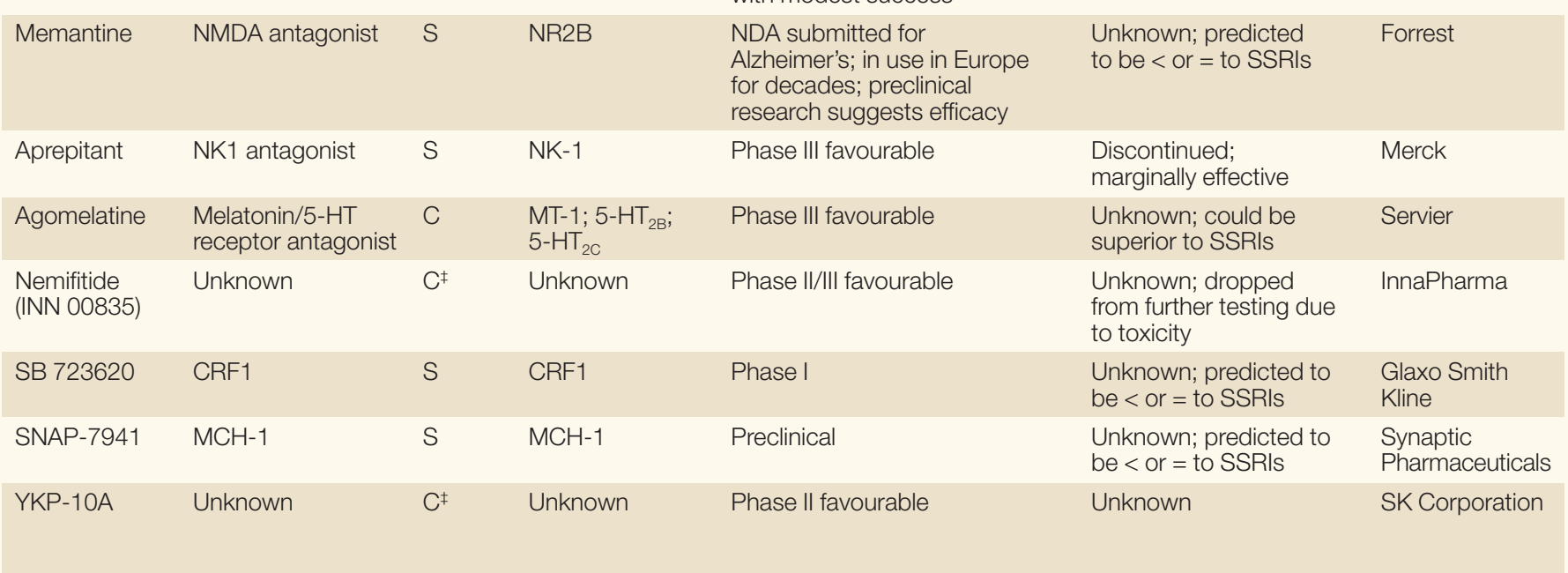

${ }^{\star} \mathrm{C}$, complex mode of action; S, simple mode of action. ${ }^{\ddagger}$ Presumed. be $<$ or $=$ to SSRls

\begin{tabular}{|c|c|}
\hline $\begin{array}{l}\text { Combination > than } \\
\text { SSRI alone in } \\
\text { uncomplicated } \\
\text { depression }{ }^{60} \text { but not } \\
\text { in refractory or chronic } \\
\text { depression }\end{array}$ & Generic \\
\hline $\begin{array}{l}\text { Unknown; predicted to } \\
\text { be >than SSRIs }\end{array}$ & Eli Lilly \\
\hline $\begin{array}{l}\text { Unknown; } \\
\text { predicted to } \\
\text { be }<\text { or = to SSRIs }\end{array}$ & $\begin{array}{l}\text { Glaxo Smith } \\
\text { Kline }\end{array}$ \\
\hline
\end{tabular}

Slight advantage $^{41} \quad$ Generic


recent colloquium sponsored by the Collegium Internationale Neuro-Psychopharmacologicum, Arvid Carlsson has argued that the field of CNS drug discovery is likely to continue to depend very much on serendipity. The approaches he suggested to facilitate these serendipitous discoveries are very similar to those outlined above, although we would argue that the results of such searches will not be serendipitous at all, but rather the result of looking for the right thing (magic shotguns) in the right place and at the right time.

Bryan L. Roth, Douglas J. Sheffler and Wesley K. Kroeze are in the Department of Biochemistry, School of Medicine, Case Western Reserve University, 2109 Adelbert Road, Cleveland, Ohio 44106, USA. Correspondence to B.L.R. e-mail:bryan.roth@case.edu doi:10.1038/nrd1346

1. Shorter, E. Looking backwards: a possible new path for drug discovery in psychopharmacology. Nature Rev. Drug Discov. 1, 1003-1006 (2002).

2. Carlsson, A. \& Wong, D. T. Correction: a note on the discovery of selective serotonin reuptake inhibitors. Life Sci. 61, 1203 (1997).

3. Hippius, H. A historical perspective of clozapine. J. Clin Psychiatry 60 (Suppl. 12), 22-23 (1999).

4. Harrison, P. J. \& Owen, M. J. Genes for schizophrenia? Recent findings and their pathophysiological implications. Lancet 361, 417-419 (2003).

5. Lewis, C. M. et al. Genome scan meta-analysis of schizophrenia and bipolar disorder, part II: Schizophrenia. Am. J. Hum. Genet. 73, 34-48 (2003).

6. Setola, V. \& Roth, B. L. Why mice are neither miniature humans nor small rats: a cautionary tale involving 5-hydroxytryptamine-6 serotonin receptor species variants. Mol. Pharmacol. 64, 1277-1278 (2003).

7. Coyle, J. T. \& Duman, R. S. Finding the intracellula signaling pathways affected by mood disorder treatments. Neuron 38, 157-160 (2003).

8. Roth, B., Sheffler, D. J. \& Potkin, S. Atypical antipsychotic drugs: unitary or multiple mechanisms for 'atypicality'. Clin. Neurosci. Res. (in the press).

9. Kane, J., Honigfield, G., Singer, J., Meltzer, H. Y. Clozapine for the treatment-resistant schizophrenic: a double-blind comparison with chlorpromazine. Arch. Gen. Psychiatry 45, 789-796 (1988)

10. Meltzer, H. Y. et al. Clozapine treatment for suicidality in schizophrenia: International Suicide Prevention Trial (InterSePT). Arch. Gen. Psychiatry 60, 82-91 (2003).

11. Colpaert, F. C. Discovering risperidone: the LSD model of psychopathology. Nature Rev. Drug Discov. 2 , 315-320 (2003)

12. Meltzer, H. Y., Matsubara, S. \& Lee, J.-C. Classification of typical and atypical antipsychotic drugs on the basis of dopamine D-1, D-2 and serotonin2 $\mathrm{pK}$ values. J. Pharmacol. Exp. Ther. 251, 238-246 (1989).

13. Altar, C. A., Wasley, A. M., Neale, R. F. \& Stone, G. A. Typical and atypical antipsychotic occupancy of $D_{2}$ and $S_{2}$ receptors: an autoradiographic analysis in rat brain. Brain Res. Bull. 16, 517-525 (1986).

14. Leucht, S., Wahlbeck, K., Hamann, J. \& Kissling, W. New generation antipsychotics versus low-potency conventional antipsychotics: a systematic review and meta-analysis. Lancet 361, 1581-1589 (2003).

15. Tuunainen, A., Wahlbeck, K. \& Gilbody, S. Newer atypical antipsychotic medication in comparison to clozapine: a systematic review of randomized trials. Schizophr. Res. 56, 1-10 (2002).

16. Fontaine, K. R. et al. Estimating the consequences of anti-psychotic induced weight gain on health and mortality rate. Psychiatry Res. 101, 277-288 (2001).

17. Kroeze, W. K. et al. $\mathrm{H}_{1}$-histamine receptor affinity predicts short-term weight gain for typical and atypical antipsychotic drugs. Neuropsychopharmacology $\mathbf{2 8}$ 519-526 (2003).

18. Meltzer, H. Y. \& McGurk, S. R. The effects of clozapine, risperidone, and olanzapine on cognitive function in schizophrenia. Schizophr. Bull. 25, 233-255 (1999).
9. Williams, G. V., Rao, S. G. \& Goldman-Rakic, P. S. The physiological role of $5-\mathrm{HT}_{2 \mathrm{~A}}$ receptors in working memory. J. Neurosci. 22, 2843-2854 (2002).

20. Woolley, M. L., Bentley, J. C., Sleight, A. J., Marsden, C. A. \& Fone, $\mathrm{K}$. C. A role for $5-\mathrm{HT}_{6}$ receptors in retention of spatial learning in the Morris water maze. Neuropharmacology 41, 210-219 (2001).

21. Castner, S. A., Williams, G. V. \& Goldman-Rakic, P. S. Reversal of antipsychotic-induced working memory deficits by short-term dopamine $\mathrm{D}_{1}$ receptor stimulation. Science 287, 2020-2022 (2000).

22. Bristow, L. J. et al. Schizophrenia and L-745,870, a novel dopamine $\mathrm{D}_{4}$ receptor antagonist. Trends Pharmacol. Sci. 18, 186 (1997).

23. Truffinet, P. et al. Placebo-controlled study of the $\mathrm{D}_{4} / 5-\mathrm{HT}_{2 \mathrm{~A}}$ antagonist fananserin in the treatment of schizophrenia. Am. J. Psychiatry 156, 419-425 (1999).

24. de Paulis, T. M-100907 (Aventis). Curr. Opin. Investig. Drugs 2, 123-132 (2001).

25. Meltzer, H., Arvantis, L., Bauer, D., Rein, W. \& Group, M. S. A placebo-controlled evaluation of four novel compounds for the treatment of schizophrenia and schizoaffective disorder. Arch. Gen. Psychiatry (in the press).

26. Rasmussen, $\mathrm{T}$. et al. The muscarinic receptor agonist BUTAC, a novel potential antipsychotic, does not impair learning and memory in mouse passive avoidance. Schizophr. Res. 49, 193-201 (2001).

27. Clark, D. et al. Is 3-PPP a potential antip sychotic agent? Evidence from animal behavioral studies. Eur. J. Pharmacol. 83, 131-134 (1982).

28. Lahti, A. C. et al. Antipsychotic properties of the partial dopamine agonist (-)-3-(3-hydroxyphenyl)- $N-n-$ propylpiperidine(preclamol) in schizophrenia. Biol. Psychiatry 43, 2-11 (1998).

29. Lahti, A. C., Weiler, M., Carlsson, A. \& Tamminga, C. A. Effects of the $D_{3}$ and autoreceptor-preferring dopamine antagonist (+)-UH232 in schizophrenia. J. Neural Transm. 105, 719-734 (1998)

30. Benkert, O., Muller-Siecheneder, F. \& Wetzel, H. Dopamine agonists in schizophrenia: a review. Eur. Neuropsychopharmacol. 5, S43-S53 (1995).

31. Kikuchi, T. et al. 7-(4-[4-(2,3-Dichlorophenyl)-1piperazinyl]butyloxy)-3,4-dihydro-2(1H)-qui nolinone (OPC-14597), a new putative antipsychotic drug with both presynaptic dopamine autoreceptor agonistic activity and postsynaptic $D_{2}$ receptor antagonistic activity. J. Pharmacol. Exp. Ther. 274, 329-336 (1995).

32. Kane, J. M. et al. Efficacy and safety of aripiprazole and haloperidol versus placebo in patients with schizophrenia and schizoaffective disorder. J Clin. Psychiatry 63, 763-771 (2002).

33. Inoue, T., Domae, M., Yamada, K. \& Furukawa, T. Effects of the novel antipsychotic agent 7-(4-[4-(2,3dichlorophenyl)-1-piperazinyl]butyloxy)-3,4-dihydro$2(1 \mathrm{H})$-quinolinone (OPC-14597) on prolactin release from the rat anterior pituitary gland. J. Pharmacol. Exp. Ther. 277, 137-143 (1996)

34. Burris, K. D. et al. Aripiprazole, a novel antipsychotic, is a high-affinity partial agonist at human dopamine $D_{2}$ receptors. J. Pharmacol. Exp. Ther. 302, 381-389 (2002).

35. Hemrick-Luecke, S. et al. Pharmacological activity of aripiprazole at presynaptic and postsynaptic dopamine receptors and in antipsychotic models. Proc. Soc. Neurosci. 894.9 (2002).

36. Lawler, C. P. et al. Interactions of the novel antipsychotic aripiprazole (OPC-14597) with dopamine and serotonin receptor subtypes. Neuropsychopharmacology $\mathbf{2 0}$, 612-627 (1999).

37. Kenakin, T. Efficacy at G-protein-coupled receptors. Nature Rev. Drug Discov. 1, 103-110 (2002).

38. Roth, B. L. \& Chuang, D. M. Multiple mechanisms of serotonergic signal transduction. Life Sci. $\mathbf{4 1}$ 1051-1064 (1987)

39. Shapiro, D. A. et al. Aripiprazole, a novel atypical antipsychotic drug with a unique and robus pharmacology. Neuropsychopharmacology $\mathbf{2 8}$, 1400-1411 (2003)

40. Santarelli, L. et al. Requirement of hippocampal neurogenesis for the behavioral effects of antidepressants. Science 301, 805-809 (2003). 41. Anderson, I. M. Meta-analytical studies on new antidepressants. Br. Med. Bull. 57, 161-178 (2001).

42. Thase, M. E., Entsuah, A. R. \& Rudolph, R. L. Remission rates during treatment with venlafaxine or selective serotonin reuptake inhibitors. Br. J. Psychiatry $\mathbf{1 7 8}$ 234-241 (2001).

43. Briley, M. New hope in the treatment of painful symptoms in depression. Curr. Opin. Investig. Drugs 4 42-45 (2003)
4. Zubenko, G. et al. Genome-wide linkage survey for genetic loci that influence the development of depressive disorders in families with recurrent, early-onset, major depression. Am. J. Med Genet. 123B, 1-18 (2003).

45. Brunner, D., Nestler, E. \& Leahy, E. In need of highthroughput behavioral systems. Drug Discov. Today 7 , S107-S112 (2002)

46. Bohannon, J. Animal models. Can a mouse be standardized? Science 298, 2320-2321 (2002).

47. Amsterdam, J. D., Brunswick, D. J. \& Hundert, M. A single-site, double-blind, placebo-controlled, doseranging study of YKP10A - a putative, new antidepressant. Prog. Neuropsychopharmacol. Biol. Psychiatry 26, 1333-1338 (2002)

48. Feighner, J. P. et al. Double-blind, placebo-controlled study of INN 00835 (netamiftide) in the treatment of outpatients with major depression. Int. Clin. Psychopharmacol. 16, 345-352 (2001).

49. Palfreyman, M. G. et al. Novel directions in antipsychotic target identification using gene arrays. Curr. Drug Target CNS Neurol. Disord. 1, 227-238 (2002).

50. Suessbrich, H., Waldegger, S., Lang, F. \& Busch, A. E. Blockade of HERG channels expressed in Xenopus oocytes by the histamine receptor antagonists terfenadine and astemizole. FEBS Lett. 385, 77-80 (1996).

51. Rothman, R. B. et al. Evidence for possible involvement of 5-HT(2B) receptors in the cardiac valvulopathy associated with fenfluramine and other serotonergic medications. Circulation 102, 2836-2841 (2000).

52. Remington, G. \& Kapur, S. SB-277011 GlaxoSmithKline. Curr. Opin. Investig. Drugs 2, 946-949 (2001)

53. Kramer, M. S., Last, B., Getson, A. \& Reines, S. A. The effects of a selective $D_{4}$ dopamine receptor antagonist $(L-745,870)$ in acutely psychotic inpatients with schizophrenia. $D_{4}$ Dopamine Antagonist Group. Arch. Gen. Psychiatry 54, 567 (1997)

54. Gewirtz, G. R. et al. BMY14802, a o receptor ligand for the treatment of schizophrenia.

Neuropsychopharmacology 10, 37-40 (1994).

55. Muller, M. J. et al. Antipsychotic effects and tolerability of the sigma ligand EMD 57445 (panamesine) and its metabolites in acute schizophrenia: an open clinical trial. Psychiatry Res. 89, 275-280 (1999).

56. van Berckel, B. et al. Efficacy and tolerance of $\mathrm{D}$-cycloserine in drug-free schizophrenic patients. Biol. Psychiatry 40, 1298 (1996).

57. Evins, A. E., Amico, E., Posever, T. A., Toker, R. \& Goff, D. C. D-Cycloserine added to risperidone in patients with primary negative symptoms of schizophrenia. Schizophr. Res. 56, 19-23 (2002).

58. Efficacy and safety of electroconvulsive therapy in depressive disorders: a systematic review and metaanalysis. Lancet 361, 799-808 (2003).

59. Stahl, S. M., Entsuah, R. \& Rudolph, R. L. Comparative efficacy between venlafaxine and SSRIs: a pooled analysis of patients with depression. Biol. Psychiatry $\mathbf{5 2}$ 1166-1174 (2002).

60. Perez, V., Gilaberte, I., Faries, D., Alvarez, E. \& Artigas, F. Randomised, double-blind, placebo-controlled trial of pindolol in combination with fluoxetine antidepressant treatment. Lancet 349, 1594-1597 (1997).

61. Berman, R. M. et al. The use of pindolol with fluoxetine in the treatment of major depression: final results from a double-blind, placebo-controlled trial. Biol. Psychiatry 45, 1170-1177 (1999).

62. Nichols, D. E. Hallucinogens. Parmacol. Ther. 101, 131-181 (2004).

63. Kroeze, W. K., Sheffler, D. J. \& Roth, B. L. G-proteincoupled receptors at a glance. J. Cell Sci. 116, 4867-4869 (2003).

Acknowledgements

Work in the authors' laboratories is supported by the National Institutes of Health.

Competing interest statement

The authors declare competing financial interests; see Web version for details.

\section{(2) Online links}

\section{DATABASES}

The following terms in this article are linked online to: LocusLink: http://www.ncbi.nlm.nih.gov/LocusLink/

CREB1

\section{FURTHER INFORMATION}

National Institutes of Mental Health Psychoactive Drug

Screening Program: http://pdsp.cwru.edu/

PDSP $K_{i}$ Database: $h t t p: / / k i d b . c w r u . e d u /$

Access to this interactive links box is free online. 